\title{
LA PROVINCIA INKA DE CHACHAPOYAS
}

Inge R. Schjellerup ${ }^{\mathrm{a}}$

\begin{abstract}
Resumen
Los inkas ingresaron al territorio de los chachapoya en la ceja de selva, al noreste de Perú, a través de fuertes enfrentamientos con las tribus semiselváticas. Trataron de destruir la naturaleza rebelde de los chachapoya durante sus sesenta años de invasión. Documentos históricos informan acerca de colonias mitmaq de los chachapoya colocados en veintiséis lugares en el Tawantinsuyu. Las investigaciones arqueológicas proporcionan evidencia de una fuerte presencia inka asociada con asentamientos chachapoya y asociados con el Qhapaq Nan. Los inkas sabian cómo transformar y adecuar el paisaje a su cosmologia. La visibilidad de las estructuras tanto chachapoya como inka eran importantes y activos en el nuevo paisaje que se utilizaba de acuerdo a las tradiciones de ambas culturas.
\end{abstract}

Palabras clave: Chachapoya, inkas, ceja de selva, conflictos, invasión, paisaje, patrones de asentamiento

\section{Abstract}

\section{THE INKA PROVINCE OF CHACHAPOYAS}

The entrance of the Inka into the territory of the Chachapoya in the cloud forest of northeastern Peru entailed strong clashes with the semi-lowland tribes here. Over their sixty years of occupation, they tried to destroy the rebellious nature of the Chachapoya. Historical documents describe the mitmaq colonies of Chachapoyas located in twenty-six places throughout Tawantinsuyu. Archaeological investigations provide evidence of a strong Inka presence associated with Chachapoya settlements and with the Qhapaq Nan. The Inkas were able to transform and alter the landscape according to their cosmology. The visibility of both Chachapoya and Inka structures were both equally important and active elements in the new landscape that were used in accordance with the traditions of both cultures.

Keywords: Chachapoya, Inkas, Ceja de Selva, conflicts, invasion, landscape, settlement patterns

\section{Referencias históricas}

La provincia inka de "Chachapoya» fue mencionada por primera vez en una carta de 1538 por Francisco Pizarro (BNL A 585: f 112R) en la que manifiesta su interés principal en encontrar un lugar agradable para fundar una ciudad y donde se pudiera encontrar oro. Francisco Pizarro conoció a los chachapoya justo después de la captura de Atahualpa, probablemente debido a la fuerte resistencia de los chachapoyas contra los inkas y la lealtad de los chachapoyas hacia los españoles. Todavía tenemos una imagen limitada de la conquista inka en la región montańosa y boscosa de los chachapoya y las referencias históricas son escasas. Sin embargo, la fuerte presencia inka encontrada durante los trabajos arqueológicos es sorprendente (Fig. 1).

La mayoría de los cronistas españoles no tenía ningún interés específico en Chachapoyas. Cieza de León (1986[1553]) nunca visitó Chachapoyas y su fuente original se desconoce, pero

\footnotetext{
${ }^{a}$ Modern History and World Cultures, National Museum of Denmark Correo electrónico: inge.schjellerup@natmus.dk
} 
da información valiosa sobre los chachapoya y su tierra. Garcilaso de la Vega (1967[1609]) utilizó a Blas Valera para su contribución sobre los chachapoya. El padre de Blas Valera era Luis Valera, quien acompañó a los primeros españoles a Chachapoyas en 1535 y, por lo tanto, Garcilaso de la Vega es una fuente única sobre la primera conquista inka de los chachapoya y sobre los incidentes posteriores que no se encuentran en otras fuentes históricas. Otras fuentes históricas que ayudarán a esclarecer el pasado de los chachapoya son documentos contenidos en las Relaciones Geográficas de Indias (1965) y otros manuscritos publicados parcialmente por Espinoza Soriano (1967); asimismo, hay fuentes inéditas de los registros coloniales administrativos y de litigios en los archivos del Perú, España e Inglaterra. Los documentos abarcan desde 1560 hasta el siglo XIX, y revelan gran cantidad sobre los curacas, comunes de indios y los encomenderos tempranos (Schjellerup 2005: 15).

\section{La conquista inka del territorio chachapoya}

La política inka del gobierno del Cusco de enviar emisarios para negociar paz o guerra mediante la diplomacia con los curacas del territorio en cuestión, no pasó antes de que el Inka hubiera recibido información de la posición estratégica de los chachapoya, como puerta de entrada hacia el este, del carácter de la gente y sus recursos naturales.

La religión de los inkas se utilizó para justificar las conquistas, con el pretexto de que la forma más pura y la más alta de la religión era adorar al creador, a los dioses del cielo y a los espíritus; el objetivo de los inkas fue de difundir esta religión en todo el mundo (Rowe 1946: 280). No puede caber ninguna duda acerca de la importancia del papel de la religión con los muchos rituales que se asociaron con actividades militares. La vida inka consistió en ideologías complejas entre sus deidades, ancestros y paisajes sagrados. Era necesario tomar augurios de los animales y de las hojas de coca, escuchar a los oráculos, cumplir con las demandas de los sacerdotes y chamanes, y tener cuidado de mantener las tradiciones y costumbres con constantes sacrificios.

Según Garcilaso, finalizando el verano, cuando Topa Inka Yupanki había conquistado la provincia de Huacrachuco al norte de Huánuco, perdió el interés en continuar la conquista de una región tan montañosa y de abundantes lluvias como la de los chachapoya. En particular, sabía que su gente era muy belicosa porque los chachapoya resueltamente respondieron a sus mensajeros de manera negativa, y se vieron obligados a tomar las armas y morir en defensa de su libertad: «que el inca hiciese lo que quisiese, que ellos no querían ser sus vasallos» (Garcilaso de la Vega 2007: 677). Pero, ¿a quién dirigía el Inka su consulta? ¿Y quién contestaba? Entonces, antes de ir a la guerra, Topa Inka Yupanki tuvo que hacer de nuevo sacrificios y el ritual de adivinación del Callpa para garantizar un resultado favorable (Fig. 2) (Guaman Poma 1613/1936: 880). No sabemos del resultado, pero decidió invadir el territorio con veinte mil soldados del sur de los charkas, caracaras, chuis y chichas, a pesar de la resistencia obvia de los chachapoya (Murra 1986: 54): «(Los chachapoya) habían hecho muchas fortalezas en sitios muy fuertes, como hoy se muestran, que todavís víven las reliquias; y habían cerrado muchos pasos estrechos que hay, demás de la esperanza que aquella tierra tiene en sí, que es tan dificultosa de andar que por algunos caminos se desguindan los indios ocho y diez estados de alto [un estado igual a 3,30 metros], porque no hay otro pasos para pasar mas adelante» (Garcilaso de la Vega 2007: 681).

Los chachapoya, un nombre que se les fue dado por los inkas, consistieron en muchos curacazgos, señoríos, o comunidades locales. En un cuestionario de 1574 se dice que «antes que fuesen conquistados los dichos indios y ayllus suso nombrados y sus comarcanos de lo dicho Topa Inga Yupanqui, estaban los dichos ayllus e indios en diferentes pueblos y parcialidades, y en cada una de ellas había un señor sin ser subjeto a otro, hasta que siendo conquistados por el dicho Topa Inga Yupanqui» (BNL A 585, f 121v; Vizcarra 1574. En Espinoza Soriano 1967: 312). Las investigaciones arqueológicas han dado pruebas de cráneos que muestran lesiones traumáticas causadas por las armas de guerra encontradas asociadas a la cerámica provincial inka (Schjellerup 2005).

Cieza de León (1986[1553]: 162) está de acuerdo con Garcilaso en que la conquista tuvo lugar desde el sur. Sarmiento de Gamboa (1960[1572]: 249) llama la atención a la conquista de la 


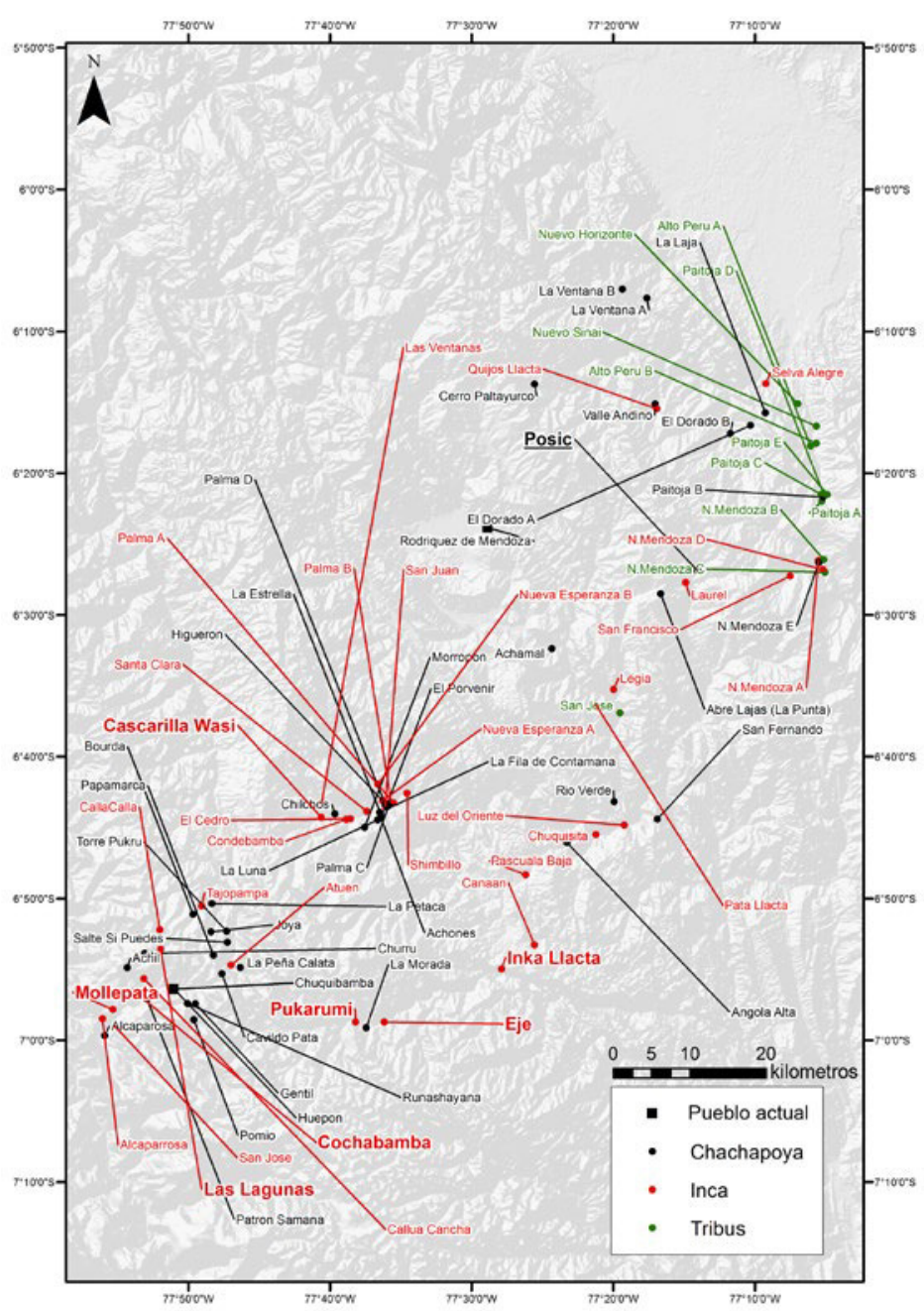

Figura 1. Instalaciones chachapoyas, inkas y asentamientos de tribus (mapa por M. K. Sørensen).

fortaleza Piajajalca (probablemente Pías) del curaca Chuqui Sota. El relato de Cabello de Valboa (1951[1586], Cap. 17: 320) le da a esta conquista un carácter de una incursión bélica más que el de una verdadera conquista, lo que probablemente haya sido el caso en muchas partes de la región. Cabello de Valboa menciona los lugares de Raimipampa, Chaymal, Xalca, Apia, y Javate (Levanto), todas localidades en la zona norte de la provincia de Chachapoyas. Topa Inka Yupanki dejó algunos parientes en Levanto (Lerche 1995: 106).

Garcilaso (2007: 681) cuenta sobre la secuencia de la incursión inka:

Desde Llauantu (Levanto) envió el gran Túpac Inka Yupanqui parte de su ejército a la conquista y reducción de una provincia llamada Muyupampa (Moyobamba), por donde entró el valeroso Ancohualla cuando desamparó sus estados, por no reconocer superioridad a los Inkas, como dijo en la vida del Inka Viracocha; la cual provincia está en los Antis, y por confederación amigable o por sujeción de vasallaje, que no concuerdan en esto aquellos indios, reconocían superioridad a los Chachas, y está casi treinta leguas de Llauantu, al levante.

Los naturales de Muyupampa habiendo sabido que toda la provincia de Chachapoya quedaba sujeta al Inka, se rindieron con facilidad y protestaron de abrazar su idolatría y sus leyes y costumbres. Lo mismo 


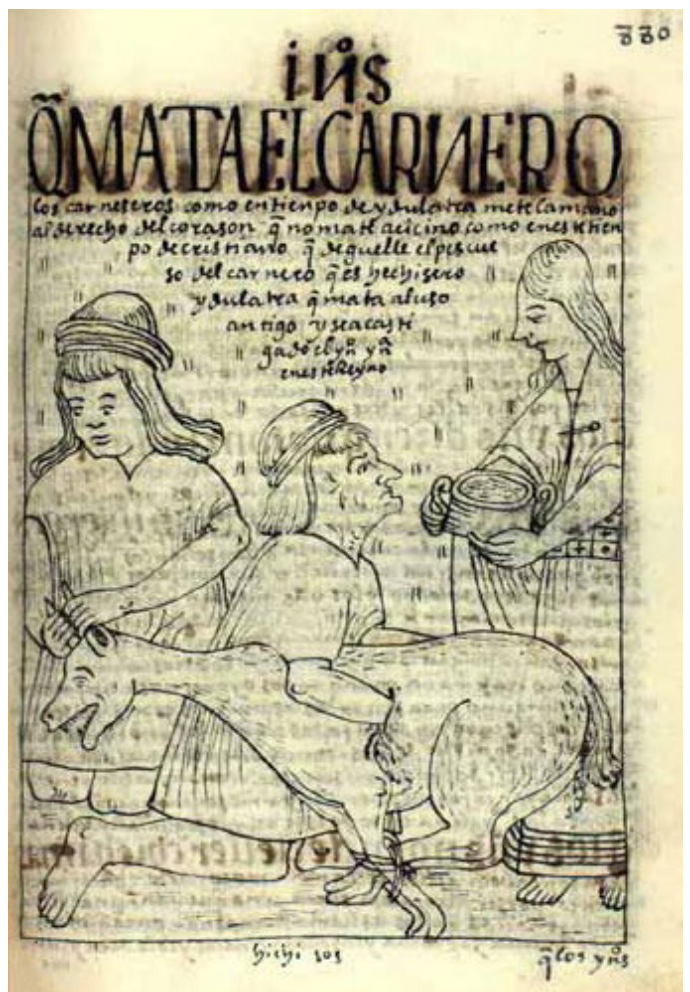

Figura 2. Guamán Poma: los andinos sacrifican una llama de acuerdo con las leyes antiguas de idolatría.

hicieron los de la provincia llamada Cascayunga, y otras que hay en aquel distrito, de menor cuenta y nombre, todas las cuales se rindieron al Inka con poco o ninguna resistencia. El cual proveyó lo necesario para la vana creencia y adoración del Sol y para el beneficio de los vassallos; mandó sacar acequias y romper nuevas tierras, para que la provincia fuese más abundante; y a los curacas dió mucha ropa, que ellos estimaron en mucho, y por entonces, mandó parar guerra hasta el verano venidero, y que alojasen el ejército y trajesen de las provincias comarcanas mucho bastimento para la gente de guerra y para los vasallos nuevamente conquistados, que por la guerra pasada padecían necesidad de comida.

Santa Cruz Pachacuti menciona que Topa Inka Yupanki tomó prisioneros de la guerra a los chachapoya para llevarlos a Cajamarca, y luego se dirigió al norte para someter a otras naciones. Santa Cruz Pachacuti (1968[1613]:302) observa que Topa Inka Yupanki, al regresar de sus expediciones contra varias etnias bélicas, entre ellos los chachapoya, tomó a «los Chachapoyas para sus alabarderos, y entonces vienen muchas mocas de los Quitos (...) Chachapoyas (...) para las Doncellas de su Coya».

\section{Territorio}

El tamaño de la provincia inka de los chachapoya se calcula haber tenido unos 30000 kilómetro cuadrados sin incluir Moyobamba, con el río Marañón como el límite occidental. Pero los otros tres límites son imprecisos e inciertos y probablemente no fueron estables durante largos períodos de tiempo, dependiendo de los intereses socioeconómicos, las alianzas, y los grupos de poder político. Supuestamente, el límite nororiental a finales de la época inkaica estaba situado donde las montañas se aplanan cerca de Pomacochas y cerca de los subgrupos de Cascayungas. 
El límite sur probablemente se encontraba hacia la demarcación política inka cerca de la provincia de Huacrachuco, pero hasta ahora no tenemos evidencias arqueológicas.

Después de la conquista, los inkas inmediatamente hicieron un plan para dividir la tierra de acuerdo a su ideología sociopolítica y religiosa y comenzaron a remodelar el paisaje cultural y sagrado, con la construcción de varias instalaciones estatales como las tierras del inka y para el culto al Sol. El límite tenía que ser tangible, para que cuando los funcionarios inkas hicieran las inspecciones del imperio supieran adónde ir para obtener información sobre la capacidad económica de la nueva provincia, la cantidad y edad de la gente para trabajar, y para seleccionar niñas para los aqllawasi: «...los tales orejones tuviesen cargo de mirar los límites y territorios que cada provincia tenía y que se los amojanasen y que si alguna provincia comarcana a ella o pueblo tuviese necesidad de tierra por la demasiada gente que tuviesen que le enviasen en pintura e arte y manera de las tales tierras y provincias para que él (el inka) las quería igualar porque iguales partes y amojanárselas» (Betanzo 1987[1551-57]: 116). Pero en una situación de conquista los inkas tenían que considerar su territorio de nuevo y cambiar sus fronteras para incluir las provincias recién conquistadas. Los inkas establecieron su control sobre los curacazgos locales, después la rivalidad tradicional entre los curacazgos fue probablemente reducida y eventualmente reducida aún más al enfrentar al enemigo común. Los Caxamarquilla, por ejemplo, hicieron frente contra Wayna Qhapaq, e inmediatamente vino a sofocar la rebelión (Sarmiento de Gamboa 1960[1572]: 260).

\section{Los chachapoya}

Los inkas llegaron a una tierra donde los chachapoya habían desarrollado una cultura dinámica y vital, con su propia utilización y mantenimiento de sus símbolos comunes, como se ve en los diseńos de la arquitectura, la cerámica y los textiles. Los chachapoya colocaron sus asentamientos monumentales en posiciones estratégicas, en grandes altitudes sobre laderas de las montańas y cordilleras, con vista a las vías de comunicación y transporte que seguían a los ríos (Muscutt et al. 1993; Schjellerup 1997, 2005; Guengerich 2014). Habían desarrollado una agricultura intensiva con una variación notable: sistemas de terrazas con muros de piedras y camellones de tierra concéntricos para el drenaje y sistemas de terrazas que parecieron anfiteatros alrededor de dolines en la jalca. Los chachapoya poseían rebaños de alpacas y llamas, minas de oro, coca, miel, acceso a la sal y al algodón. Los bosques estaban llenos de animales salvajes, guacamayos (loros), otras aves de colores, y madera que servía de leña para quemar en los sacrificios. El paisaje además estaba lleno de recursos que servían como símbolos, incluyendo un lago en la forma de una serpiente, fuentes de ríos y rocas de formas extraordinarias. Los chachapoya no solo eran conocidos como fieros guerreros, sino también como inteligentes agricultores, talentosos tejedores, hechiceros o chamanes, médicos de hierbas y constructores de puentes (Schjellerup 2005).

Teniendo en cuenta los diversos y valiosos recursos, tanto materiales como inmateriales, que la región de los chachapoya poseía, es comprensible que los inkas querían tener el control total de la zona.

\section{La política y administración inka}

Topa Inka Yupanki introdujo la unidad ideal de administración del huno, con divisiones en guarangas y pachacas y seleccionó a Cochabamba como el centro religioso y administrativo de este huno en su segunda visita a la región de Chachapoyas (BNL A 585 f 114r, 121 r, Vizcarra 1574). Más tarde la provincia de Chachapoyas se dividió en tres hunos, cada uno al cargo de su propio curaca (Espinoza Soriano 1967: 299). El sitio inka de Cochabamba estuvo en el cruce de un ramal paralelo del Qhapaq Nan de Cuzco, vía Huánuco y por el oeste por el camino de Cajamarca. Fue visitado por tres Inkas: Topa Yupanki, Wayna Qhapaq y Atawallpa (Schjellerup 2005). 
En los años siguientes algunos de los curacazgos, especialmente el de Caxamarquilla, se rebelaron ante los inka en tres oportunidades, en una instancia siendo los inkas emboscados por los pomacocha (Murúa 1968[1611]: 155). La pena fue dura si alguno se oponía al orden del Inka: describe Garcilaso (2007: 341) como, en tiempo de Wayna Qhapaq «en pueblo de los Chachapoyas porque un indio regidor antepuso las tierras del curaca, que era su pariente, a las de una viuda, lo ahorcan, por quebrantador del orden que el Inca tenía dado en labrar de las tierras, y pusieron la horca en la misma tierra del curaca». Betanzos (1987[1551-57], Cap. XLIV: 188-90) hace una observación interesante sobre Wayna Qhapaq: que fue a Levanto en Chachapoyas en otra expedición militar para obtener la coca y el ají necesarios para el funeral de su madre Mama Oqllo. Se dice que permaneció allí tres años, con un contingente de 100.000 guerreros como su guardia personal (sin duda exagerada para mostrar su magnitud). Algunos de los principales sitios inka ubicados a 1900 msnm se encuentran en las zonas productoras de coca, donde hay una abundante presencia de coca silvestre, aún hoy en día, las cuales poseen hojas especialmente largas.

La construcción de muchas instalaciones inka de sur a norte deben haber tenido lugar en esos años, y los restos arqueológicos hablan de una fuerte actividad Inka (Schjellerup 2005, Schjellerup et al. 2003, 2005, 2009).

Como parte de su política administrativa, los inka empezaron a destruir la naturaleza rebelde de los chachapoya y trasladaron veintiséis grupos chachapoya como mitimaqkuna a otras partes del Tawantinsuyu (Vaca de Castro 1908: 44, 445; Levillier 1940: 143, 159; Ramos Gavilán 1976 [1621]: 84; Moreno Yáńez 1980; Salomon 1986). Las fuentes históricas no indican cuántas personas chachapoya fueron transferidas de forma compulsiva. Pero en caso de Topa Inka Yupanki, él trajo más de doscientos indios chachapoya que estaban bajo el curaca Apo Llajas, y los puso en la comarca de Amaybamba como mitmaqkuna, "haziendoles traer todo genero de semilas y que abia en ella asi de paltas como de lucumas y maíz y ají mas de coca de unos frutos especiales para confeccionar sus brevajes» (Rostworowski 1963: 225). Si los veintiséis grupos se formaron cada uno con doscientos indios en promedio, entonces representaron un movimiento por lo menos de cinco mil personas, número considerable durante la ocupación de los inka. El hijo de Apo Llajas Chuquillasac cayó prisionero durante uno de los encuentros de los chachapoya contra los inka durante la huida de Manco II a Vitcos. Manco le mandó cortar la cabeza en el puente de Chuquichaca y arrojarle río abajo (Rostworowski 1963: 226). Sin embargo, el registro de las fuentes históricas habla de relativamente pocos mitmaqkuna de otras partes del Tawantinsuyu que se encontraron en la región de Chachapoyas. Huancas fue un grupo mitmaq colocado por Wayna Qhapaq cerca de la ciudad actual de Chachapoyas (Colin 1907: 469). Se menciona que Waskhar envió doscientos chupachos a guarniciones en Chachapoyas (Helmer 1955-56: 40), pero hasta ahora no se ha encontrado evidencia de ellos.

\section{El camino inka o Qhapaq Nan}

El Qhapaq Nan obviamente utilizaba los caminos o senderos anteriores en toda la región montañosa, pero los inka los mejoraron en todas las partes con empedrado de piedra, canales de drenaje y escaleras. Desde el centro administrativo inkaico de Cochabamba, el Qhapaq Nan se dirigió no solo hacia el oeste y en direcciones norte-sur, sino también hacia el este hasta la ceja de selva. El Qhapaq Nan siguió los sistemas fluviales de Yonán, del río Chilchos, río Verde, río Huabayacu y río Huambo hacia el este. Otro camino pasó de Levanto y Chachapoyas hacia el este a Moyobamba. Esta ruta principal de transporte y comunicación se utilizó durante siglos después de la conquista inka. A grandes distancias el camino es empedrado y con muchas escaleras, pero solo con unas pocas instalaciones inka (Figs. 3 y 4 ) (observación personal de la autora, 2014). Hubo un alto grado de comunicación entre la sierra y la ceja de selva hasta el final del siglo XVI y, posteriormente, en el siglo XVII y adelante (Church 1996; Schjellerup et al. 2003). 


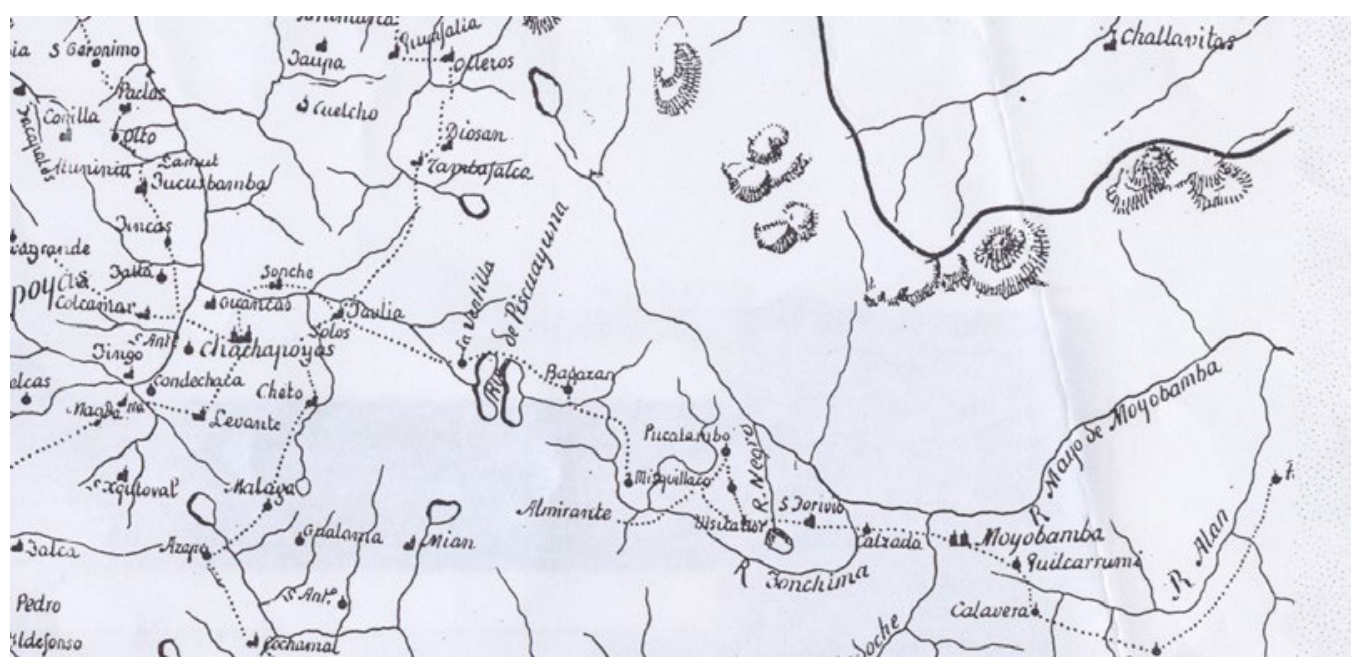

Figura 3. Parte del plano de la Intendencia de Trujillo, MS 1767d. (Cortesía del British Museum).

Todas las instalaciones inkas están conectadas con los caminos inkas. Muchos tampus pequeños son casas o kanchas, como Tampu Calla Calla, Incencio (Schjellerup 2005), Canaán, Chuquisita, Pampa Vado (Schjellerup et al. 2003), Chasquitambo, Las Ventanas, El Porvenir (Schjellerup et al. 2005), Laurel (Schjellerup et al. 2009), y en las lagunas de Pishcohuañuna. Otras instalaciones inkas son más grandes, como Cochabamba, Atuén, Tampu Eje, Pucarumi (Schjellerup 2005), Inka Llacta, Pata Llacta (Schjellerup et al. 2003), Pampa Hermosa, Tampu Quijos Llacta, y Pósic (Schjellerup et al. 2009), los cuales tienen varias casas, kanchas, kallankas, canales y fuentes (baños).

\section{Instalaciones inkas}

En lo sucesivo, se da una descripción de varias de las instalaciones inka en Chachapoyas. Factores ambientales y sagrados eran importantes en la selección de lugares que tendrían con la posibilidad de remodelar el paisaje. Los centros administrativos fueron construidos en terreno plano o nivelado, algunos rodeados de terrazas de piedras y rocas que protegen los sitios al lado de los ríos; y caminos inkas elevados y con muros de contención. Hubo una amplia gama de instalaciones inka. Parece que los inkas desde su primera entrada querían hacer su presencia visible en los paisajes mediante la arquitectura, así que muchos de los sitios estaban probablemente todavía en construcción a la llegada de los españoles.

\subsection{Cochabamba}

El complejo de Cochabamba está situado en una meseta de la montaña, a una altitud de 2800 msnm, cerca de una pequeña laguna. El diseño del complejo de Cochabamba se dispersa en el paisaje del drenaje de Challua Cancha, y de esta manera es muy diferente a los asentamientos nucleados de otros centros administrativos inkas más grandes como Huánuco Pampa en Huánuco y Pumpu en Junín.

Cochabamba tiene seis sectores, entre ellos tres de élite y dos canales cubiertos de piedra: Moyambol es un asentamiento construido al estilo chachapoya situado en el sur, en una inclinada ladera de la montaña; Pucallpa es una estructura tipo kancha con una orientación al oeste en la ladera de la montaña; Chose y Pucallpa son dos filas de estructuras de almacenamiento, con la misma orientación al oeste, en la ladera de la montaña; Mollepata tiene tres construcciones con 


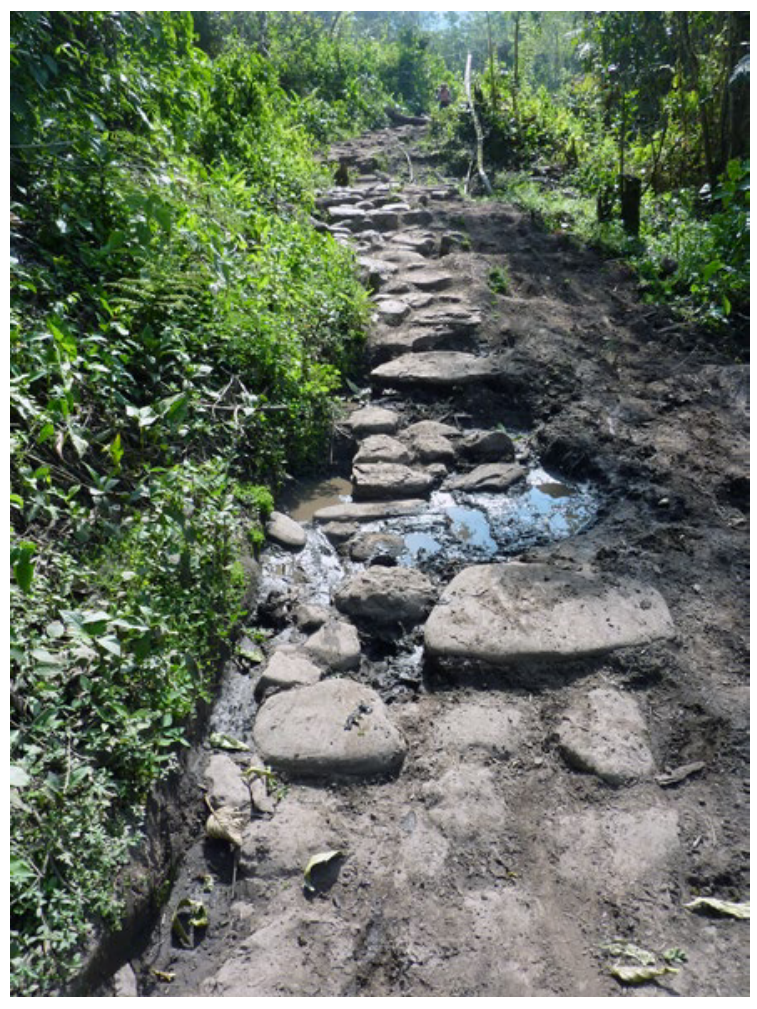

Figura 4. El Qhapaq Nan entre Molinopampa y Pukarumi (foto por I. Schjellerup).

una fuente doble más abajo de Cochabamba en la montaña; y finalmente, Challua Cancha es un santuario al pie de la meseta de Cochabamba.

La parte central de Cochabamba se compone de dos sectores de élite con dos portales con doble jamba de albañilería del estilo Cuzco Imperial (Figs. 5, 6) y con estructuras de kancha y kallanka. Dos canales cubiertos de piedra traen agua de cada uno de los lados de la montańa a dos fuentes hundidos de estilo Cusco Imperial, resaltando la ideología inka del tinku. Uno de los canales, corre desde la laguna Occlo Cocha a ocho kilómetros al norte y está tallado en la roca arenisca. Durante la fase de construcción, grandes obras de nivelación y drenaje se llevaron a cabo para obtener un nivel plano para los edificios en el sector norte (Schjellerup 2005: 220). Un usnu es mencionado por los habitantes locales, quienes dicen que estuvo colocado donde está actualmente la iglesia, en la plaza del pueblo de Cochabamba. Piedras de moler y triturar se han encontrado en Cochabamba y la tradición oral habla de una mina de oro muy cerca.

Moyambol, al frente de Cochabamba, tiene alrededor de un centenar de casas redondas y parece haber sido un asentamiento chachapoya que probablemente fue trasladado por los inka, desde su lugar de origen en las zonas altas, para controlar a la gente rebelde y usarla en diversos trabajos.

Pucallpa tiene una estructura tipo kancha con un conjunto de almacenes, está situado en una pendiente del lado suroccidental de la montaña. El diseño tiene la característica de una kancha inka cerrada e incluye dos estructuras circulares (Fig. 7). El material cerámico excavado es inka provincial policromo, que da cuenta de un lugar con cierta importancia y prestigio. La presencia de una fuente bien construida es otro elemento importante en la planificación inka del sitio, con un significado útil y simbólico en el asentamiento. Veintitrés colcas fueron construidas en la ladera de la montańa cerca de Pucallpa. Las estructuras rectangulares están dispuestas en dos hileras y cuentan con ductos de ventilación en las paredes y el drenaje. Una huella en el nivel del suelo indica cómo fue colocado el material almacenado, probablemente bultos de tubérculos, dejando espacio alrededor del material. 


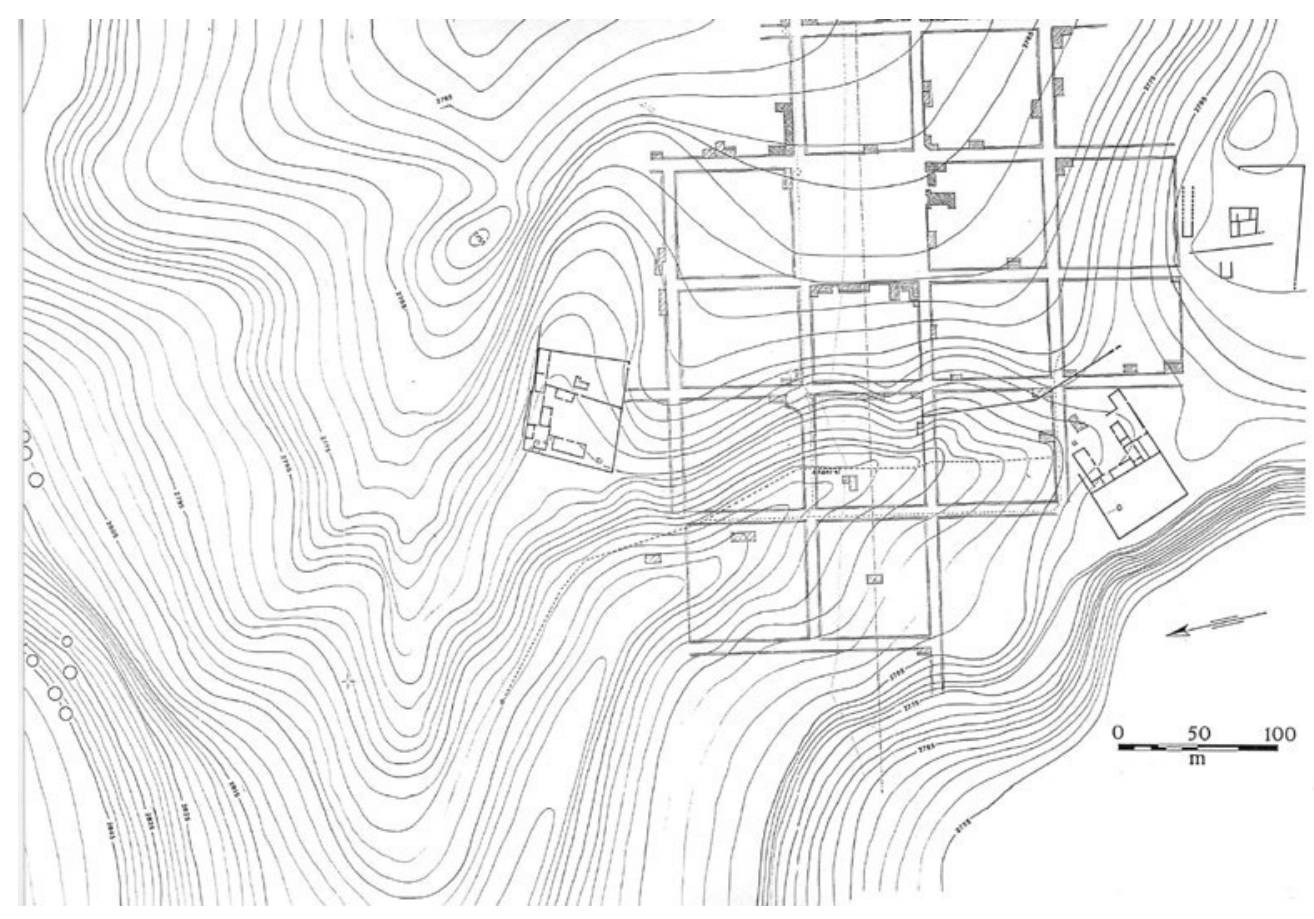

Figura 5. Plano de Cochabamba (dibujo por L. Jorgensen).

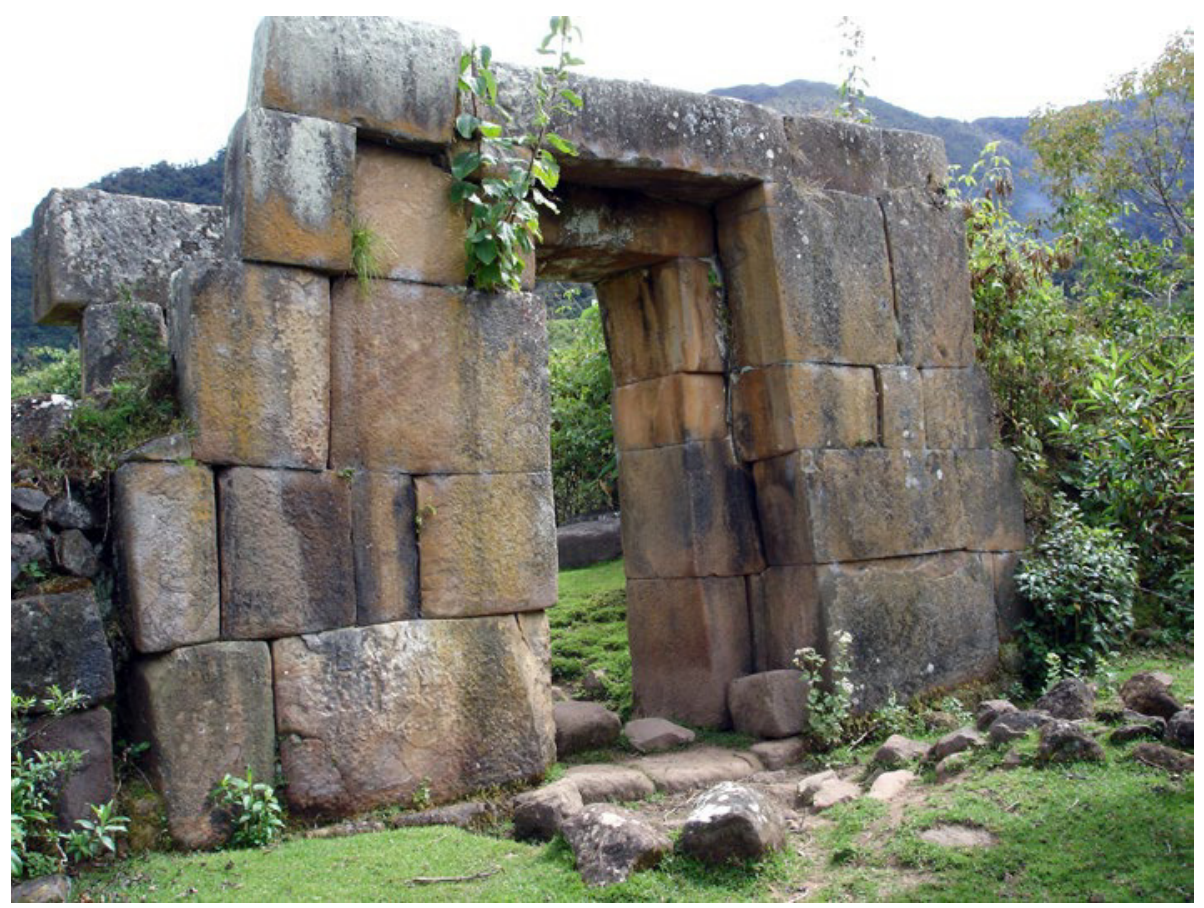

Figura 6. Portada inka en Cochabamba. (foto por I. Schjellerup). 


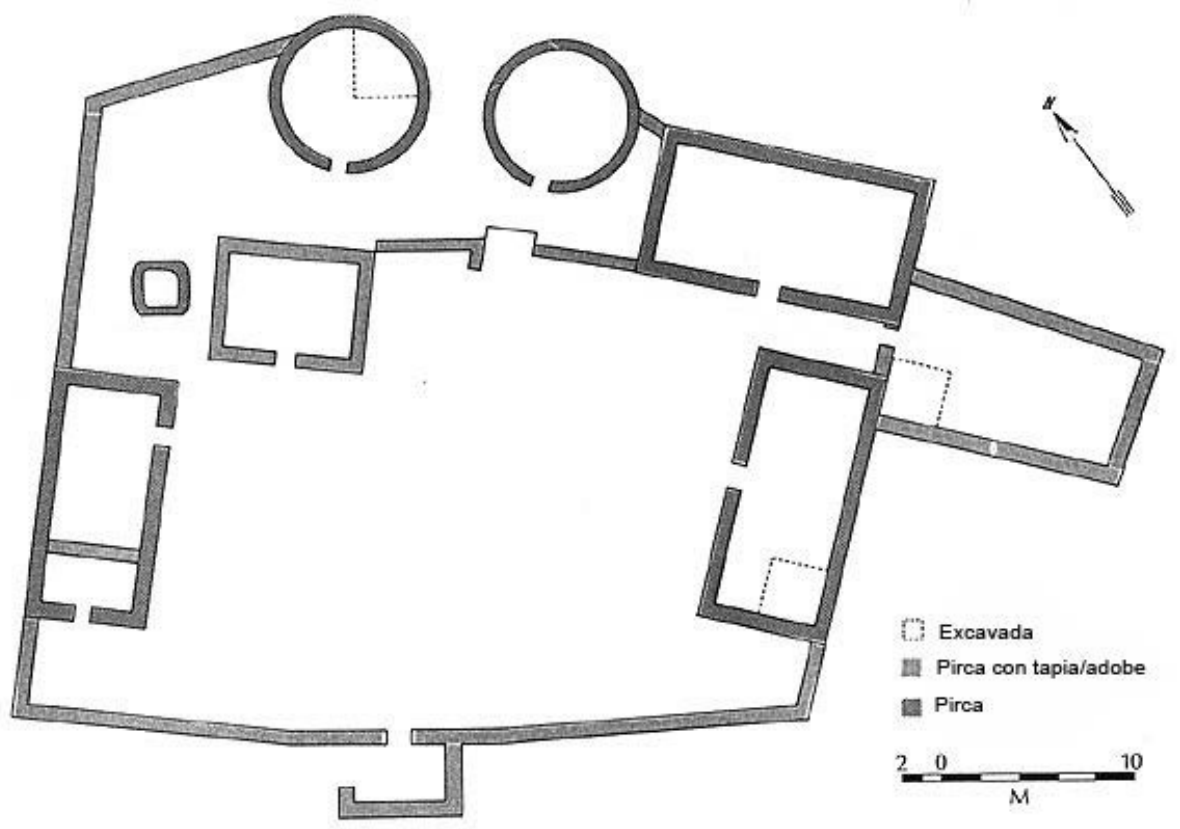

Figura 7. Plano de Pucalpa (dibujo por L. Jørgensen).

Tanto Mollepata como Challua Cancha están situados cerca del Qhapaq Nan. Mollepata está a una altitud de $1900 \mathrm{msnm}$ y tiene una vista espectacular sobre el valle. Tiene solo tres construcciones situadas en una terraza, rodeadas por un muro de piedras, de las cuales una es karpa wasi, una estructura de tres lados. La parte superior de las construcciones fue hecha en adobe (Fig. 8). Al frente de la karpa wasi está una fuente doble con la pared posterior en albañilería del estilo Cuzco Imperial.

Challua Cancha está a una altitud de $2470 \mathrm{msnm}$. Es un estanque semisubterráneo y ovoide, rodeado por una doble pared de pirca que incluye dos rocas naturales. Dentro del estanque, casi en el centro, se construyó hacia el noreste, una plataforma de piedra amurallada ovalada. La estructura se encuentra cerca del río Challua Cancha. El estanque probablemente fue un santuario inka, que incluía rocas sagradas cerca del camino y cerca del río.

\subsection{El Tampu de las Lagunas}

El Tampu de las Lagunas se encuentra saliendo de Cochabamba justo antes de cruzar el puerto de la cordillera de Calla Calla, cerca de una roca muy prominente que debe haber conformada la huaca mencionada por Albornoz [1570] (en Duvilos 1967: 33): «Callacalla es guaca de los dichos chachapoyas conchabamba. Es una piedra en un cerro que se llama Callacalla, tres leguas del pueblo de Cochabamba» (Fig. 9). Varios sitios chachapoya como Achil, Chibul, Runashayana, y Gentil están situados en las cimas de las montañas cercanas, con una vista completa de la meseta de Cochabamba (Schjellerup 2005).

\subsection{Atuén}

El Qhapaq Nan pasa al este de Atuén, que es una zona que se encuentra a una altitud de $3550 \mathrm{msnm}$. El nombre Atuén es problamente una distorsión de la palabra quechua hatun, «el Grande». Los inka construyeron un sitio impresionante en la orilla de la Laguna La Sierpe, es decir, una laguna con forma de serpiente que es el origen del río Utcubamba (Fig. 10). Varias casas rectangulares, un usnu, 


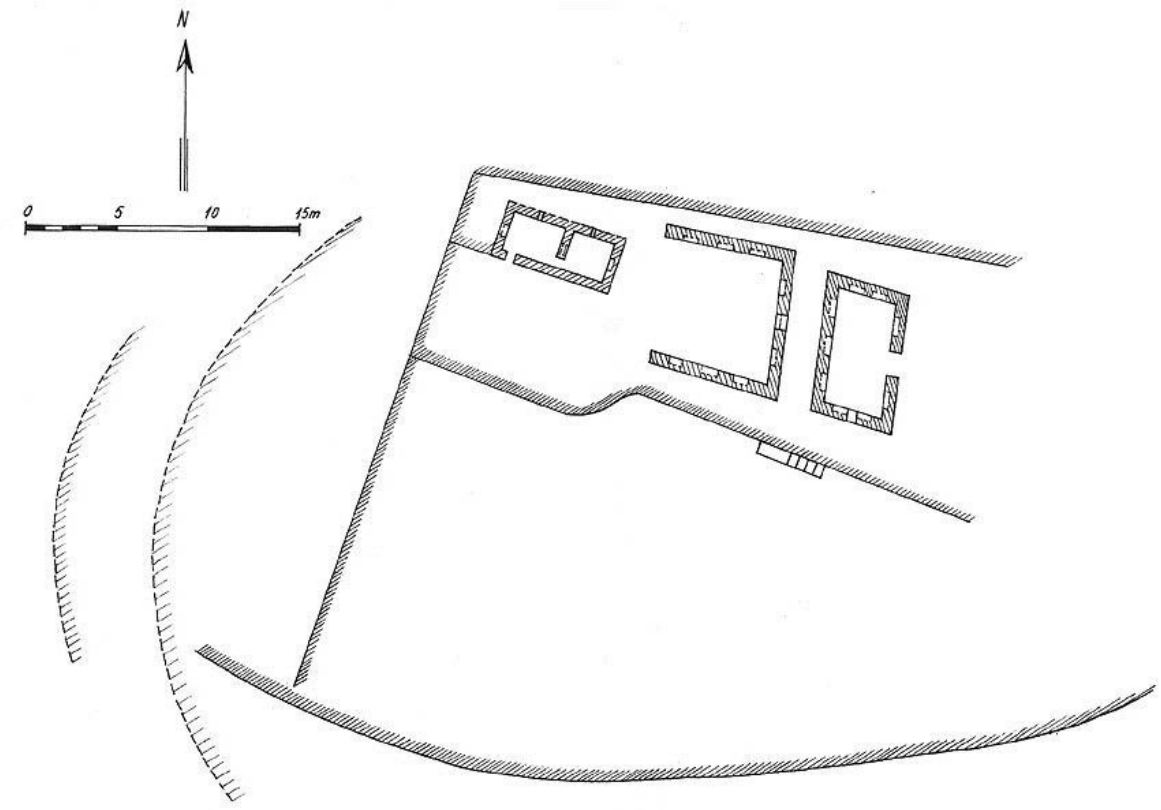

Figura 8. Plano de Mollepata (dibujo por O. Angulo Zavaleta e I. Schjellerup)

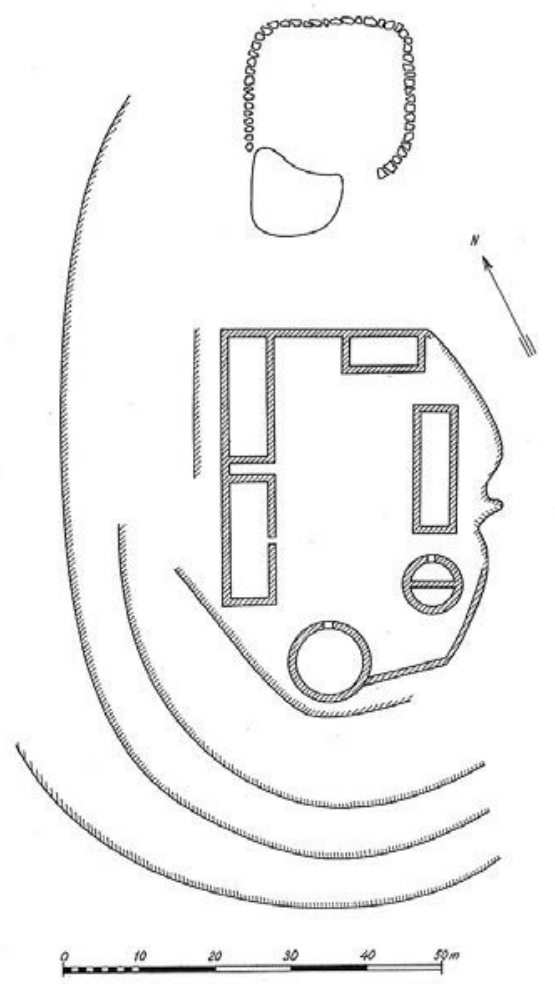

Figura 9. Plano de Tampu Las Lagunas (dibujo por N. Bech e I. Schjellerup). 


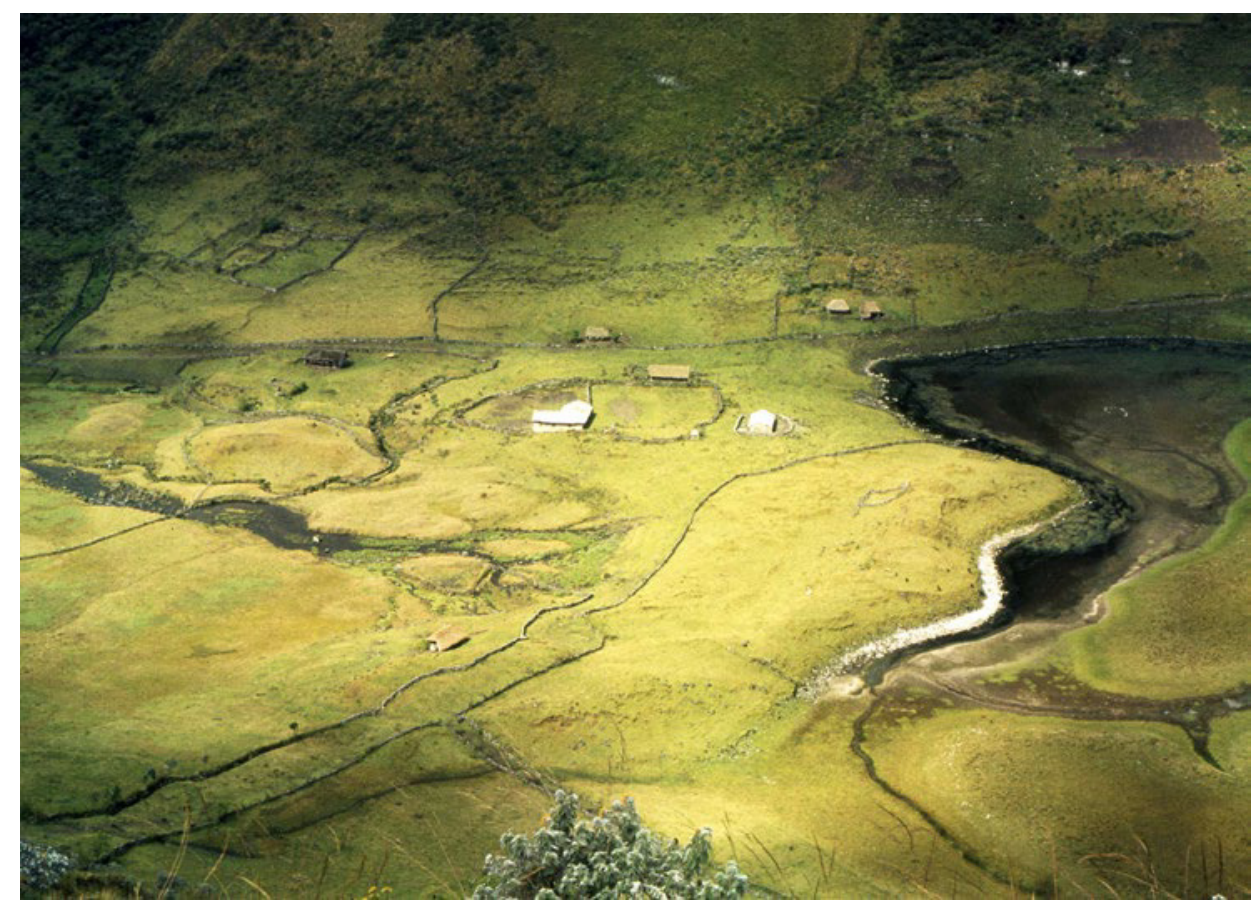

Figura 10. Laguna La Sierpe en Atuén. (foto por I. Schjellerup).

una estructura tipo kancha y dos fuentes fueron construidos cerca de los dos sitios chachapoya de La Peña Calata y de Cabildo Pata. Además, un sistema de terrazas de piedras para cultivar tubérculos fue construido por los inkas cerca de La Peña Calata. La tradición oral habla del lugar como una suerte de «spa» de Huayna Cápac, quien se supone estuvo aquí durante algún tiempo (Schjellerup 2005: 270).

\subsection{Los Chilcho}

El valle de los Chilchos, ubicado al este de Leimebamba, era una de las entradas hacia el este y al territorio considerado yunga. Los chilcho formaron parte del sistema de los curacazgos chachapoya, como un grupo étnico específico de la ceja de selva, con sus propios curacas. Uno de los primeros curacas de los chilcho, mencionado en los documentos españoles, es Chilcho, señor de los indios anayunga, chontaces, y mitimaes (BNL AGI 123, Ramo 4,2r). Se ilustra la conexión yunga y la supremacía de los chilcho sobre los chontaces, un grupo que probablemente estaba dedicado a la agricultura y al cultivo y la producción de la palma de chonta. La palma de chonta se utiliza para hacer lanzas y alabardas, que eran las armas utilizadas por el pueblo de chachapoya. Por ejemplo, 1200 chachapoya y cañari fueron seleccionados para servir al Inka Waskhar en el Cuzco como sus alabarderos y asistentes de su casa (Santa Cruz Pachacuti 1968[1613]: 312), como Topa Inka Yupanki lo había hecho antes. Varias lanzas de chonta también se han encontrado en las cámaras funerarias de los chachapoya (Museo del Ministerio de Cultura, Moyobamba).

La mención de cinco guarangas del cacique principal Don Hernando Chilcho en el momento de la conquista española (BNL A 585, f 97V) sugiere más asentamientos y casas residenciales de las que se han registrado hasta ahora. 


\subsection{Cascarilla Wasi}

Cascarilla Wasi, ubicado a una altitud de $2000 \mathrm{msnm}$, está situado en una llanura nivelada cerca del Qhapaq Nan y la naciente del río Chilchos. El sitio muestra características de un centro administrativo inka con los rasgos de casi todos los sitios inka de la región. Tiene una kallanka, una construcción tipo kancha, una fuente y una estructura dividida por tres recintos simétricos, presumiblemente una qollqa. Dos estructuras circulares se encuentran al norte de la fuente (Fig. 11). Su ubicación está en un punto estratégico de control, por donde la gente entró al valle de los Chilchos desde el oeste de Leimebamba y desde sur de la Laguna de los Cóndores. El sitio está relacionado con el comienzo del río Chilchos, un sitio sagrado de los inka (Schjellerup et al. 2005). La cantidad de terrazas en las laderas de las montañas es testimonio de un uso intensivo del fértil valle de los Chilchos, que proporcionó excelentes condiciones para la agricultura, como el cultivo del maíz y la producción de algodón, lo cual continuó en el período colonial (Schjellerup et al. 2005). Caminos interconectados empedrados prehispánicos recorren todo el valle, los inka hicieron buen uso del valle como una de las entradas hacía al este.

\subsection{Llactacocha}

Llactacocha, al otro lado de la Laguna de los Cóndores, es un sitio chachapoya con ocupación inka. Probablemente albergó a los habitantes de las cámaras funerarias en la empinada ladera de la montaña. Estas cámaras funerarias probablemente fueron utilizadas por los chachapoya y luego por los inka. Las cámaras con más de 200 momias dieron evidencia de los excelentes tejidos mencionados como una de las habilidades de los chachapoya por Cieza de León, y se han encontrado utensilios de los inkas como khipus y cerámica inka provincial (von Hagen 2002; Guillen 2002; Bjerregård 2007).

Los sitios inka más pequeños se encuentran más adentro del valle, como Chasquitambo, una estructura rectangular que ha mantenido su nombre inicial. Otros asentamientos menores combinan sitios chachapoya con arquitectura inka, probablemente con el fin de control. Desafortunadamente, la mayoría de los sitios arqueológicos en el valle de los Chilchos han sido destruidos debido a la agricultura y la ganadería actual.

\subsection{Tampu Eje}

Tampu Eje está ubicado al lado del Qhapaq Nan, en ruta a la instalación inka de Inka Llacta por el río Huabayacu a una altura de $1850 \mathrm{msnm}$. Tampu Eje fue construido en un área nivelada y sostenido por varias terrazas de piedra que llegan hasta el río. Consta de una plaza grande, una kancha cerrada con tres casas, una kallanka con dos fuentes hundidas y un grupo de tres casas. El sitio da la impresión de estar en proceso de construcción. Las tres casas una frente a la otra, parecen ser el comienzo de otra kancha, y montones de piedras fueron encontrados en el lado oriental del sitio para su posterior construcción. Con el fin de proteger las estructuras de los daños ocasionados por las abundantes lluvias, se construyó un sistema de andenería de piedra encima de la kallanka y la kancha (Schjellerup 2005: 297) (Fig. 12).

\subsection{El Complejo Pukarumi}

El complejo Pukarumi, a 1960 msnm, está situado en una zona angosta en la unión entre dos ríos, el Huabayacu y el Israel. El complejo está rodeado por muros de piedra de espesor variable por los cuatro lados. Una rampa empedrada conduce al sitio, que consiste en cinco sectores, incluyendo una gran plaza nivelada, una estructura tipo kancha cerrada con tres construcciones hacia el sur, dos fuentes - una hundida - y una gran kallanka. Dos estelas de piedra arenisca de color rojo, tienen decoración incisa de símbolos como el sol, espirales, volutas, meandros, una figura de honda junto con brazos y piernas y otras figuras. Estas estelas colindan con el lado de la rampa. 

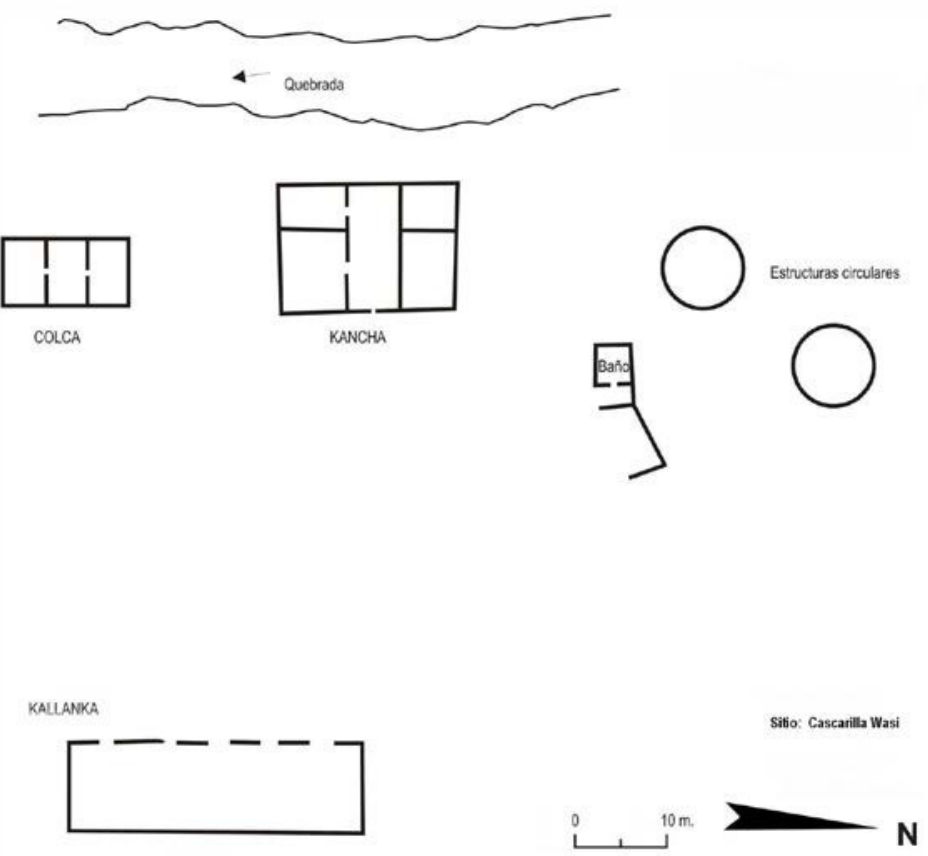

Figura 11. Plano de Cascarilla Wasi (dibujo por I. Schjellerup).

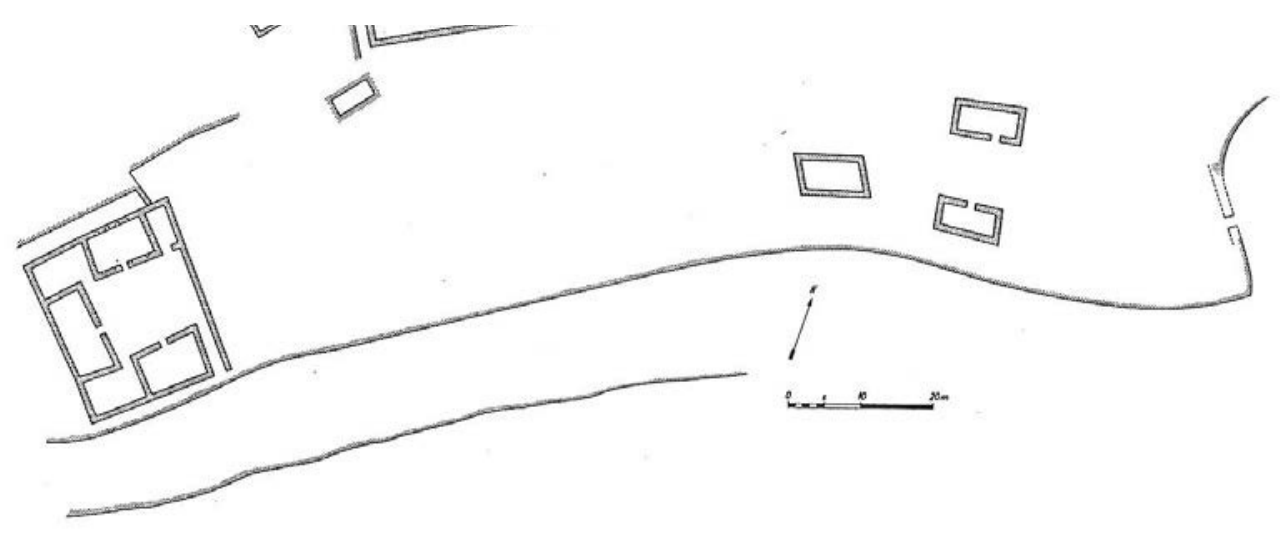

Figura 12. Plano de Tampu Eje (dibujo por O. Angulo Zavaleta, V. Peña Huaman e I. Schjellerup). 


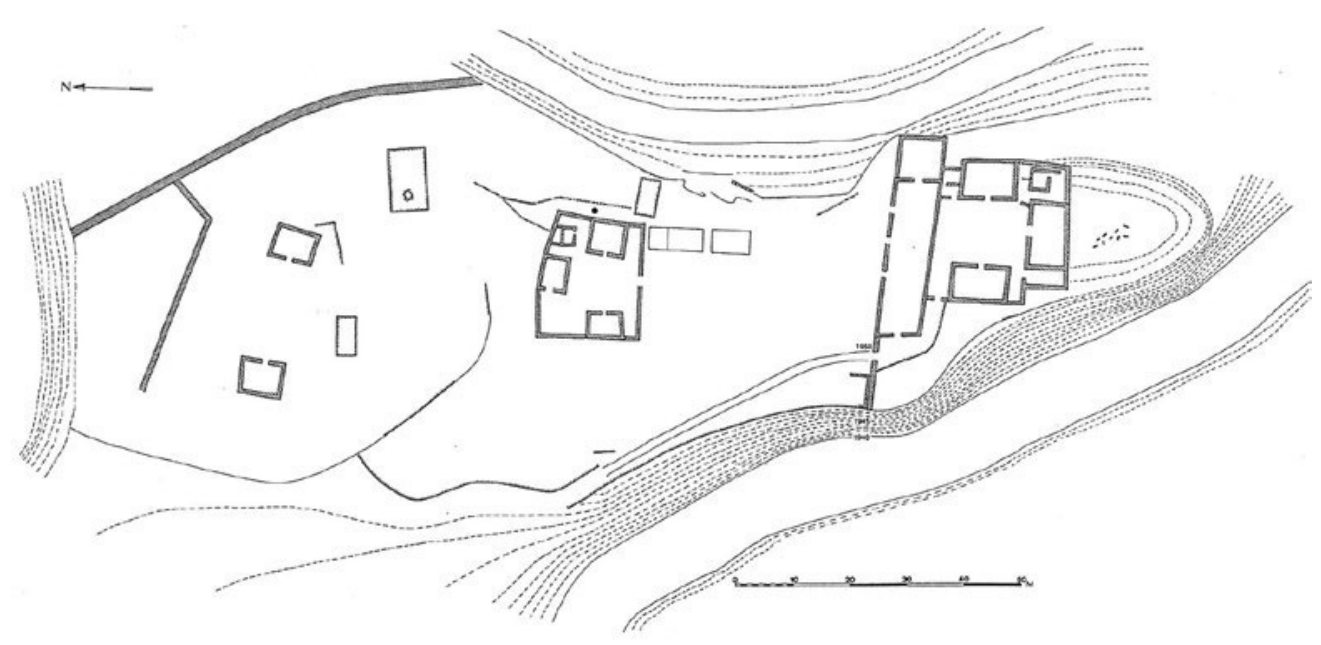

Figura 13. Plano de Pukarumi (dibujo por M. Vedsø e I. Schjellerup).

El sector medio tiene una estructura menor tipo kancha cerrada con tres construcciones y una fuente abierta. Agua para ambas fuentes fue conducida en canales cubiertos desde la montaña detrás del complejo. El sector norte incluye dos estructuras rectangulares y dos plataformas, una de los cuales parece haber sido un usnu cubierto con piedras; la cámara interior contenía carbón quemado. El sitio muestra una notable combinación de un complejo fortificado defensivo cerrado con un profundo carácter ceremonial entre dos ríos (Fig. 13). Viajeros tenían que pasar a través de Pukarumi para continuar a lo largo del río por el Qhapaq Nan, y este probablemente significó que fue necesario involucrarse en la participación en ceremonias rituales y obtener el permiso para continuar el viaje.

\subsection{Inka Llacta}

Inka Llacta está situado a una altitud de 1975 msnm y tiene terrazas de piedra hacia el sur y el norte. Inka Llacta tiene tres sectores que consisten en: una zona principal de la élite, dos estructuras tipo kancha, una plataforma con dos kallankas, y un tampu más arriba en la montaña. Un canal divide el sitio, este que se construyó parcialmente en una depresión natural, en el lecho de la roca, pero se ha sido cortado y presenta paredes de piedra en ambos lados. El canal recorre 150 metros con una caída de aproximadamente 10 metros. La zona principal, de élite, tiene quince estructuras además de una estructura de planta rectangular y una fuente de estilo Cuzco Imperial, elaborada en piedra arenisca roja. Una línea tallada en las piedras superiores de la estructura rectangular, que da la vuelta en toda la estructura, se asemeja a la banda de oro alrededor del templo Qorikancha en el Cuzco (Cobo 1990[1580-1657]: 50) (Figs. 14 y 15). La piedra arenisca no se encuentra de forma natural en la área cercana, pero sí a dos días de viaje, cerca del sitio arqueológico de Pascuala Baja (Schjellerup et al. 2003).

Las investigaciones botánicas mostraron parientes silvestres de las especies domesticadas del pepinillo o tomate de árbol (Solanaceae), la papaya (Caricaceae), el pajuro (Fabaceae) y la ciruela de monte (Bunchosia armeniaca). Los análisis del polen dieron pruebas del cultivo de maíz, frejol y plantas frutales. Desafortunadamente, mucho del polen de los sitios inka se encuentra en mal estado de conservación (Schjellerup et al. 2003: 275). La presencia de Inka Llacta con arquitectura del estilo Cusco Imperial en medio de la densa ceja de selva nos da nueva luz sobre la conquista inka y la política en esta parte nororiental y remota del Tawantinsuyu, la cual debió de requerir 


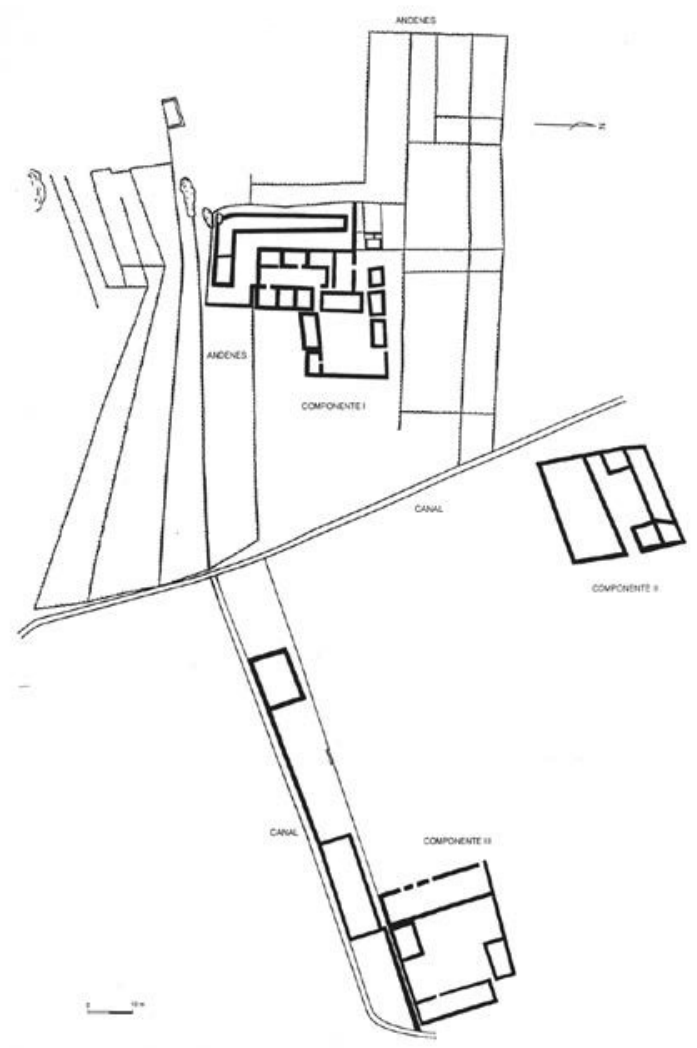

Figura 14. Plano de Inka Llacta (dibujo por V. Peña, A. Tandaypata e I. Schjellerup).

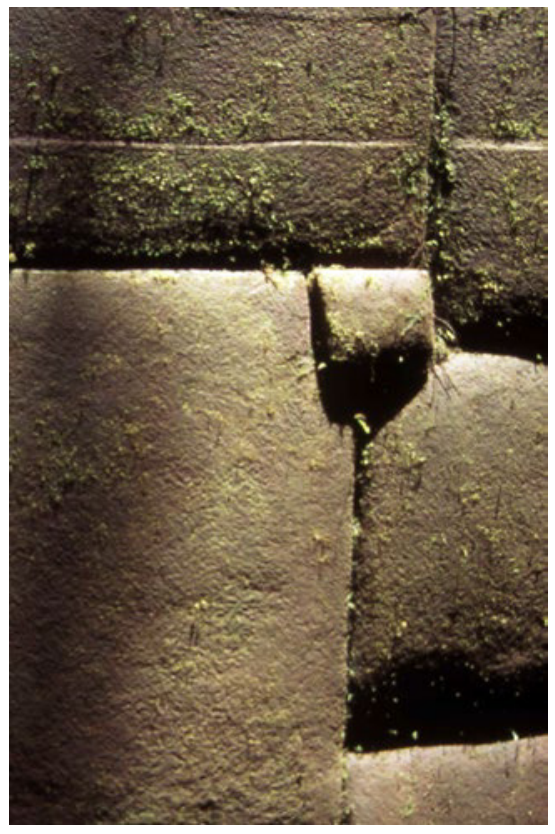

Figura 15. La linea tallada en las piedras superiores de la estructura rectangular en Inka Lacta (foto por I. Schjellerup). 
de bastante trabajo para su mantenimiento. La decisión de ubicar un sitio en el bosque implica la tala de árboles de un área grande, la introducción de árboles frutales y mantenimiento constante para sacar malas hierbas, además del peligro que representan los árboles que se extienden grandemente. El sitio debe haber aparecido un oasis abierto en el denso bosque (Schjellerup et al. 2003). No hemos encontrado restos del camino inka por la densa vegetación, pero la ruta continúa hacía el norte pasando por otras instalaciones inka de Tampu Caanan, Pascuala, Chuquisita, hasta encontrar el río Verde y el río Huambo (Schjellerup et al. 2003).

\subsection{El complejo Pósic}

El complejo Posic se ubica en la margen izquierda de la quebrada Mashuyacu, a una altura de 1940 msnm, en otro sistema del camino inka que va desde el valle de los Chilchos al noreste hacia Moyobamba. Es conocido en la tradición oral por tener oro y sal, dos recursos importantes. Pósic tiene no menos de tres sectores principales que representan a tres grupos de su población: los chachapoya, los inkas y las tribus locales (Figs. 16 y 17). El sitio arqueológico está construido en una ladera ligeramente inclinada entre dos ríos, con vista a las montañas hacia el sur. El área central fue nivelada para construir una kancha doble, una gran kallanka, una kancha menor, una fuente, un usnu en albañilería del estilo Cuzco Imperial, un canal y dos intiwatanas. La presencia de dos intiwatanas es excepcional. Ambas reflejan una montaña detrás de ellas, la cual tiene vegetación de arbustos bajos y orquídeas, completamente diferente de las otras montańas de los alrededores, que son más bien boscosas (Figs. 18 y 19). Hacia el norte y el sur se construyó un elaborado sistema de terrazas de piedras. Estas terrazas parecen ser de un período de construcción a principios de los chachapoya, con pirkas y rocas muy grandes, que tienen algunas protuberancias peculiares con fines rituales. El sector chachapoya se encuentra cruzando el río Mashuyacu con casas circulares y plataformas rituales. Un camino empedrado atraviesa toda la zona y continua más arriba en las montańas.

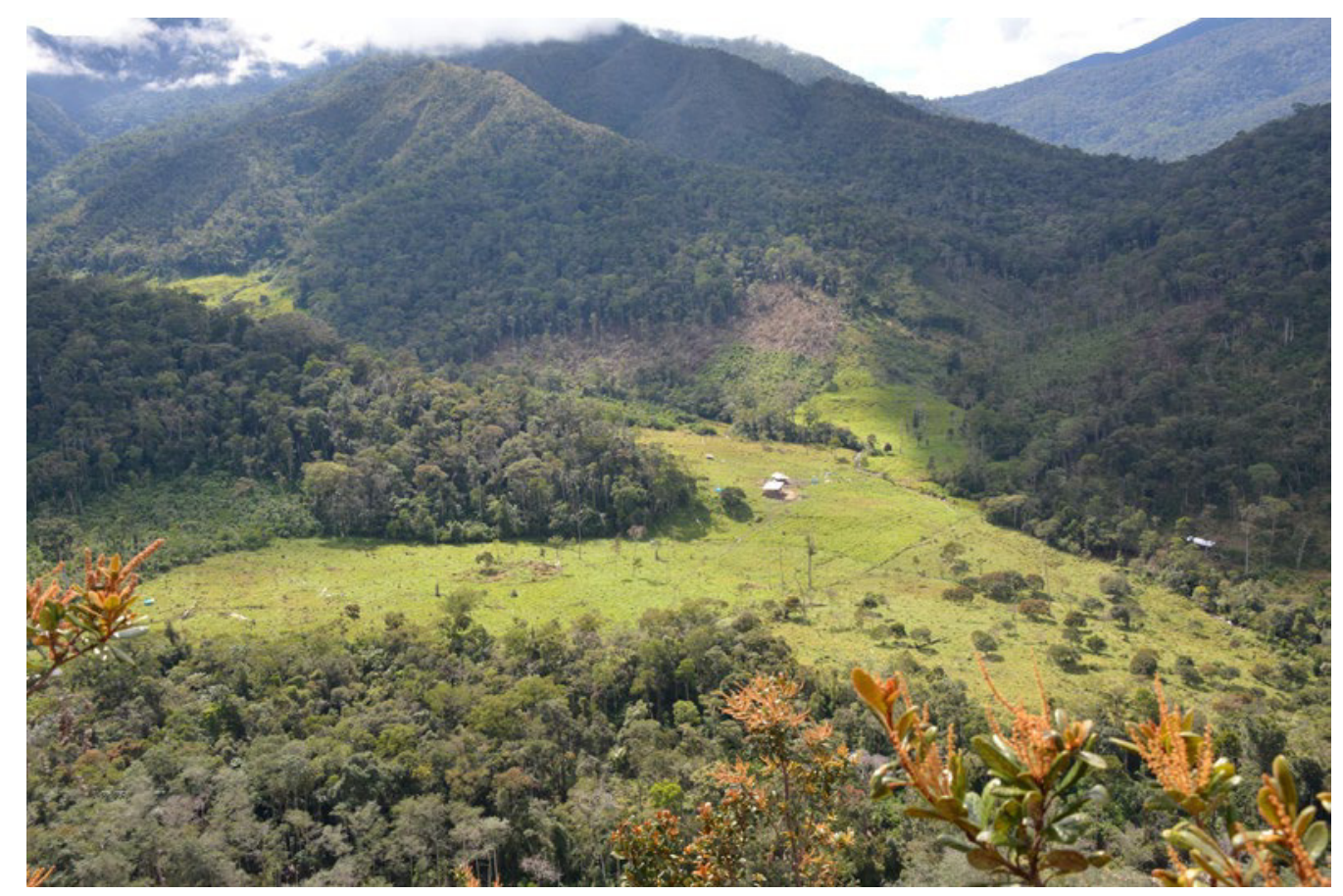

Figura 16. Paisaje del sitio inka en Pósic. (foto por I. Schjellerup). 


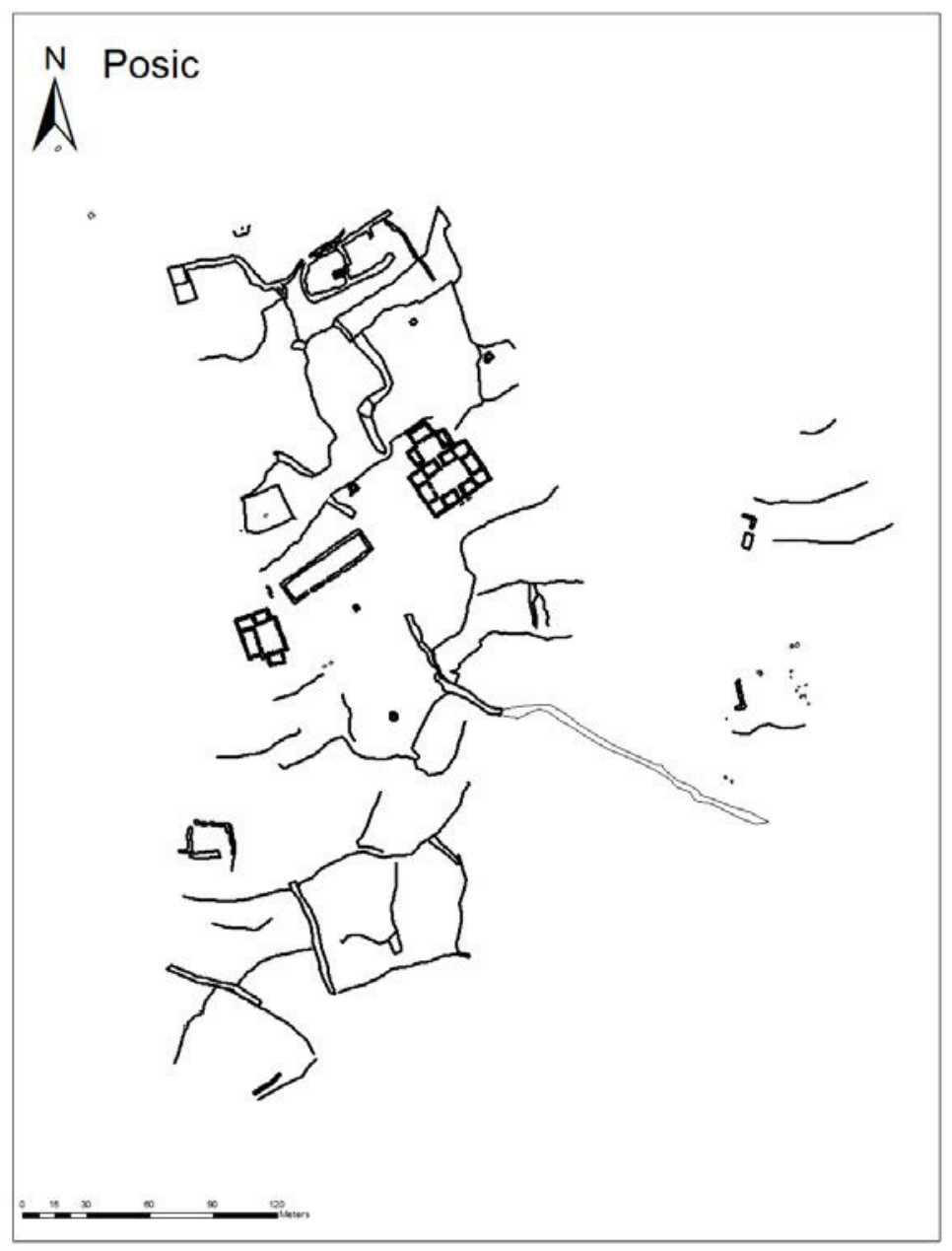

Figura 17. Plano de Pósic (dibujo por L. Jorgensen y R. Pommer).

Más de veinticinco rocas y piedras de gran tamaño tienen petroglifos en forma de pequeños hoyos, combinados, en algunas de las más grandes con largas líneas incisas. La mayoría de estos petroglifos se encuentra cerca del sector arqueológico inka. Ninguno de los petroglifos parece pertenecer a ninguna de las dos culturas chachapoya o inka; sin embargo, son probablemente evidencia de una población tribal anterior que pudo haber utilizado el lugar para ceremonias especiales (Fig. 20) (Schjellerup et al. 2009).

\section{Discusión}

El Señorío Chachapoya que controlaba muchos curacazgos en la región, administraba un gran territorio con asentamientos instalados, de preferencia, en la cima de las montańas. Desarrollaron agricultura intensiva, utilizando sofisticadas técnicas, como por ejemplo, los sistemas de drenaje para ampliar áreas de cultivo. El territorio Chachapoyas, después de la conquista inka, fue organizado como una provincia del Tawantinsuyu, conservando ciertos aspectos de la tradición chachapoya. Debido a la ubicación geográfica, este territorio presenta una gran gama de paisajes 


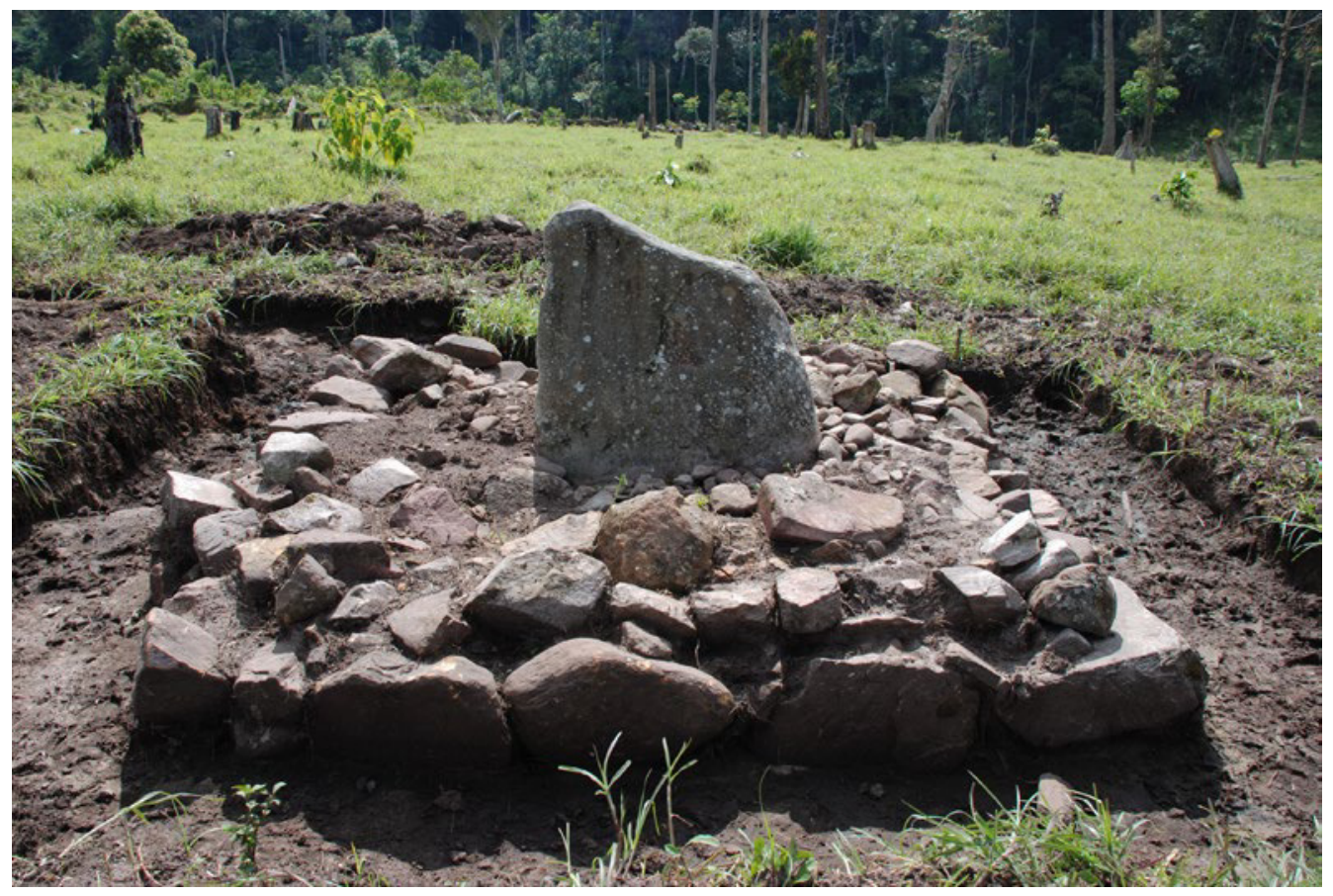

Figura 18. Intiwatana 1, sitio Pósic (foto por I. Schjellerup).

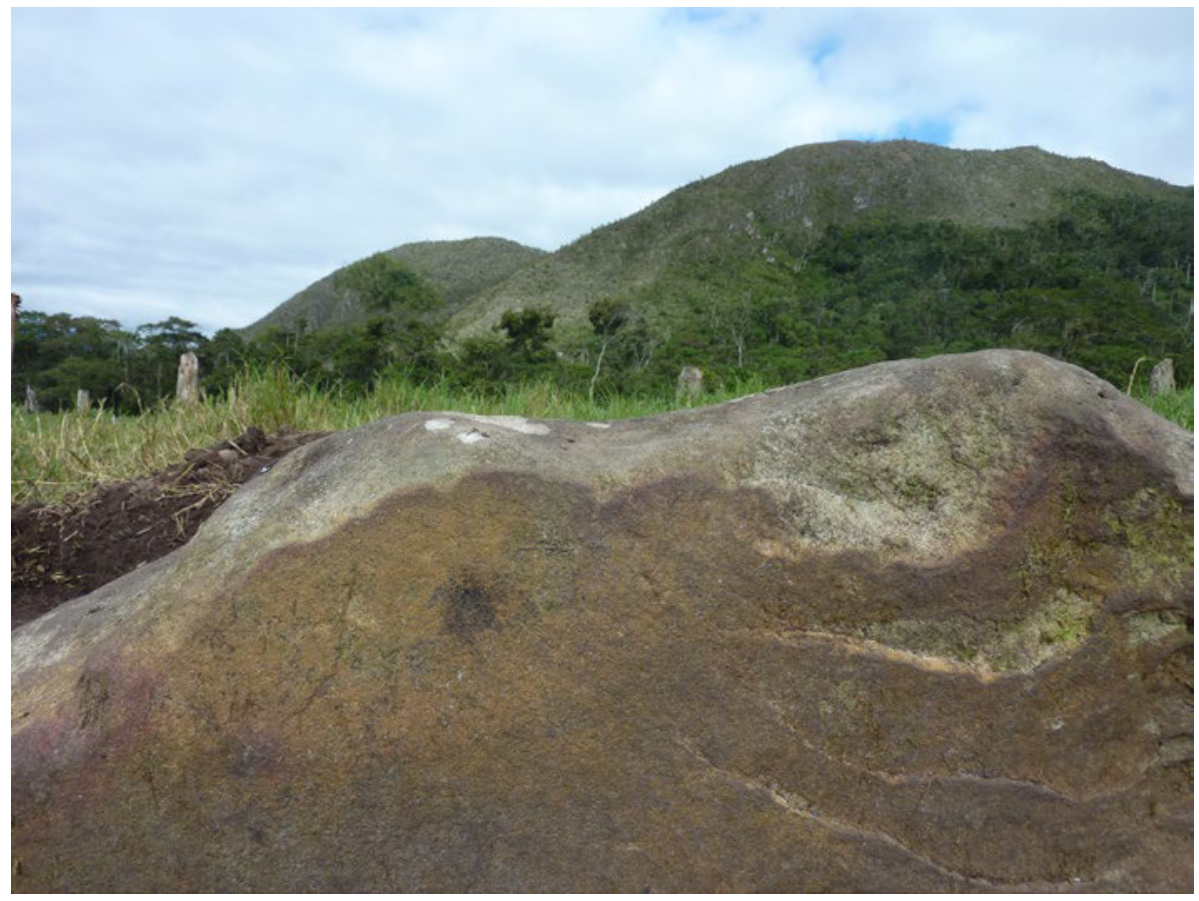

Figura 19. Intiwatana 2, Pósic (foto por I. Schjellerup). 


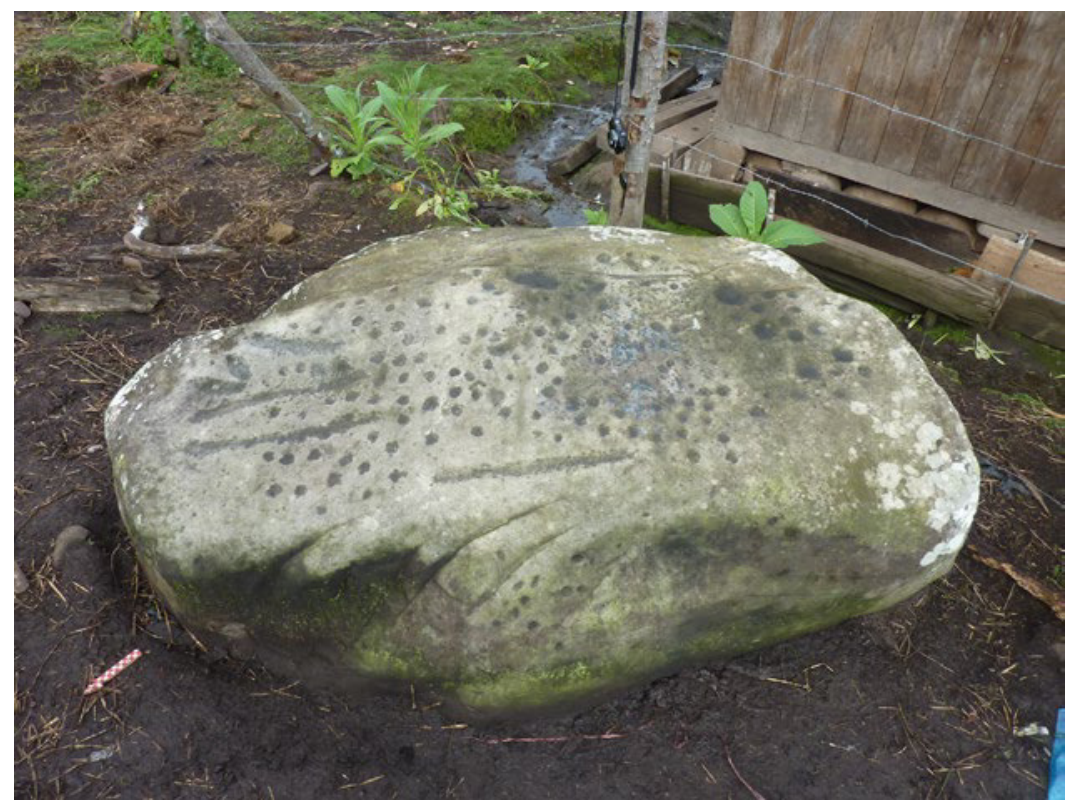

Figura 20. Piedra con petroglifos, Pósic (foto por I. Schjellerup).

y nichos ecológicos. Los inkas siguiendo su patrón de edificaciones, buscaron lugares con paisajes específicos, generalmente de acuerdo a sus principios económicos y cosmológicos, para establecer sus instalaciones, así como la habilitación de caminos como el Qhapaq Nan para transporte y como marcadores geopolíticos. Es evidente la influencia inka en la región, impulsando la construcción de recintos de planta cuadrangular y rectangular, la nivelación de suelos y la habilitación de muros de contención, transformando finalmente, el ambiental original de Chachapoyas en paisaje cultural Inka. Desde el punto de vista arqueológico, chachapoyas e inkas compartieron el mismo territorio, cada cual dejando su influencia en la transformación del paisaje local.

Los sitios inka se pueden agrupar jerárquicamente como se observa, en instalaciones pequeñas y aquellas más grandes. La mayoría de los sitios inka se ubicaron cerca de los asentamientos de los chachapoya para controlar su población, y debido a la importancia económica y agrícola de tales sitios. Muchos lugares también fueron elegidos por la geografía sagrada, como: nacimientos de ríos, una laguna en forma de serpiente, un cruce entre dos ríos, ríos que desaparecen en el suelo y rocas con formas sobresalientes. La mayoría de los sitios inka se encuentra en altitudes más bajas que los de los chachapoya.

Los inkas tenían que mantener los caminos e instalaciones para mantenerlos libres de la vegetación que crece rápidamente, y cuidarlos de los animales peligrosos como jaguares y víboras siempre presentes en la densa selva. Los sitios inkas a alturas de entre 1100 y $2150 \mathrm{msnm}$ se ubican dentro de la zona de leishmaniasis (uta). Gade (1979: 1999) menciona ejemplos de documentos tempranos de la post-conquista sobre gente que se mudó a las comunidades de la sierra desde las chacras en las áreas tropicales de la montaña, como adaptación especial para hacer frente a este tipo de enfermedades.

La presencia inka llenó el paisaje con símbolos importantes para su existencia en la región extranjera de los chachapoya. La ocupación inka consistió en ideologías complejas de sus deidades, ancestros y paisajes sagrados. Los inkas tenían que asegurarse del mantenimiento de su infraestructura religiosa e impresionar a los chachapoya con rituales casi constantes, siguiendo el calendario que tenían en el Cuzco. Los conceptos de la teatralidad y dramatismo provocaron y promovieron el reconocimiento que se expresó en los aspectos ideológicos como parte del control económico y político. 
En este breve tiempo de aproximadamente sesenta años, hubieron graves consecuencias para la población y su subsistencia. Pero solo últimamente estamos empezando a saber más acerca de la fuerte presencia de los inka y su forma de utilizar la tierra de los chachapoya.

La evidencia arqueológica, las fuentes históricas, los informes etnográficos y botánicos, así como los resultados de la antropología física y de las ciencias naturales nos han permitido lograr una mejor comprensión de las transformaciones en la historia cultural de los chachapoya.

\section{Agradecimientos}

Agradezco a los participantes en mis proyectos arqueológicos que durante muchos años han resistido el trabajo en el campo en tiempos lluviosos, con barro y lodo, todos tristes, y en el sol con alegría y risa, a Víctor Peña Huamán, Víctor Quipuscoa Silvestre, Lars Jørgensen, Rune Pommer, Anna Guengerich, y Rómulo Ocampo Zamora.

\section{Bibliografía}

\section{Fuentes primarias}

Archivo General de Indias (AGI), Patronato Real, Legajo 123 Ramo 4 Información de los meritos y servicios del Capitán Juan Perez de Guevara, uno de los conquistadores y pacificadores del Perú y particularmente de la provincia de los Chachapoyas. Año 1578.

Biblioteca Nacional Lima (BNL) A 585 Expediente repartimiento de Leymebamba y Cochabamba, encomienda de Francisco de Guevara. Chachapoyas, 6 de Mayo 1577.

\section{Fuentes publicadas}

Albornoz, C. de

1967 La instrucción para descubrir todas las guacas del Pirú y sus camayos y haziendas, en: P.

[1570] Duviols (ed.), Un inédit de Cristóbal de Albornoz: la instrucción para destruir todas las guacas del Pirú y sus camayos y haziendas, Journal de la Société des Américanistes 56(1), 7-39, Paris.

Betanzos, J.

1987 Suma y narración de los Incas, Edición Atlas, Madrid

[1551-57]

Bjerregård, L. (ed.)

2007 Chachapoya textiles. The laguna de los Cóndores textiles in the Museo Leymebamba, Chachapoyas, Peru, Museum Tusculanum Press/University of Copenhagen.

Cabello Valboa, M.

1951 Miscelánea antártica, Universidad Nacional Mayor de San Marcos, Lima.

[1586]

Cieza de León, P. de

1986 Crónica del Perú, Primera Parte, 2a edición, Fondo Editorial PUCP, Lima.

[1553]

Church, W.

1996 Pre-historic cultural development and interregional interaction in the tropical montane forest of Peru, tesis de doctorado, Department of Anthropology, Yale University, New Haven.

Colin, R. P.

1907 El pueblo de Huancas, Boletín de la Sociedad Geográfica de Lima, año XVII, t. XXI, 465-470.

Cobo, B.

1990 Inca religion and customs [traducción de R. Hamilton], University of Texas Press, Austin. [1580-1657] 


\section{Espinoza Soriano, W.}

1967 Los señoríos étnicos de Chachapoyas y la alianza hispano-chacha, Revista Histórica 30, 224-333.

Garcilaso de La Vega, I.

2007 Comentarios reales de los Incas, tomo I-IV, reproducción de 1ra edición, Universidad Nacional Mayor de

[1609] San Marcos, Lima.

Guaman Poma de Ayala, F.

1936 Nueva crónica y buen gobierno, Institut d' ethnologie.

[1613]

\section{Guengerich, A.}

2014 Monte Viudo: residential architecture and the everyday production of space in a Chachapoya Community, tesis de doctorado, Department of Anthropology, University of Chicago, Chicago.

Guillén, $S$.

2002 The mummies of the Laguna de los Condores, en: E. Gonzáles y R. León (eds.), Chachapoyas, el reino perdido, 345-387, AFP Integra, Lima.

\section{von Hagen, A.}

2002 Chachapoya iconography and society at Laguna de los Condoers, Peu, en: H. Silverman and W. Isbell (eds.), Andean Archaeology, Volume II: Art, Landscape and Society, 137-155. Kluwer Academic/Plenum, New York.

\section{Helmer, M.}

1955/56 La visitación de los yndios Chupachos. Inka et Encomendero 1549, Travaux de l'Institut Francais d'Etudes Andines 3, 3-50, Paris/Lima.

Lerche, P.

1995 Los Chachapoya y los símbolos de su historia, Servicios Editoriales César Gayoso, Lima.

\section{Moreno Yánez, $S$.}

1980 Colonias mitmas en el Quito incaico: su significación económica y política, copia mimeografiada, Quito.

\section{Murúa, Fray M. de}

1986 Historia general del Perú. Ed. Manuel Ballesteros, Historia 16. Crónicas de América, Temi, Madrid.

[1611]

Muscutt, K., V. R. Lee y D. Sharon

1993 Vira Vira, un nuevo sitio Chachapoya, Wilson.

Ramos Gavilán, A.

1976 Historía de Nuestra Señora de Copacabana. Segunda edición completa, según la impresion principe de 1621.

[1621] Academia Boliviana de la Historia. La Paz.

Rowe, J.

1946 Inca Culture at the Time of the Spanish Conquest, en J. Steward (ed.), Handbook of South American Indians, Volume 2: the Andean Civilizations, 183-330, Smithsonian Institution, Washington, D.C.

Santa Cruz Pachacuti Yamqui, J.

1968 [1613] Historia de los Incas y Relación de su Gobierno. Biblioteca de Autores Españoles, Vol. 109. Madrid.

Salomon, F. L.

1986 Ethnic Lords of Quito in the Age of the Incas: The Political Economy of North-Andean Chiefdoms. Cornell University, Ithaca

Sarmiento de Gamboa, P.

1960 Historia Indica. Biblioteca de Autores Españoles, 135, 193-279. Madrid.

[1572]

Schjellerup, I.

1997 Incas and Spaniards in the Conquest of the Chachapoyas. Archaeological, Ethnohistorical and Anthropological Research in the North-eastern Peru. GOTARC Series B. Gothenburg Archaeological Theses. No.7. Göteborg University, Göteborg.

2002 Reflexiones sobre los chachapoya en el Chinchaysuyu. Boletin de Arqueología PUCP 6, primera parte, 43-56. 
2005 Incas y españoles en la conquista de los chachapoya, Pontificia Universidad Católica del Perú, Fondo Editorial, Instituto Francés de Estudios Andinos, Lima.

Schjellerup, I., M. K. Sørensen, C. Espinoza Camus, V. Quipuscoa Silvestre, V. Peña Huaman

2003 Los valles olvidados, pasado y presente en la utilización de recursos en la ceja de selval The forgotten valleys, past and present in the utilization of resources, Ethnographic Monographs 1, The National Museum of Denmark, Copenhagen.

Schjellerup, I., V. Quipuscoa Silvestre, C. Espinoza Camus, V. Peña Huaman, M. Kamp Sørensen

2005 Redescrubriendo el valle de los Chilchos, condiciones de vida en la ceja de selva, Perul The Chilchos Valley revisited, life conditions in the Ceja de Selva, Ethnographic Monographs 2. The National Museum of Denmark, Copenhagen.

Schjellerup, I., C. Espinoza Camus, J. Rollefson, V. Quipuscoa Silvestre, M. K. Sørensen

2009 La Ceja de Montaña, un paisaje que va desapareciendol A disappearing landscape. Estudios interdisciplinarios en el noreste del Peru/Interdisciplinary Studies from north- eastern Peru, The National Museum of Denmark, Ethnographic Monographs 3. Copenhagen.

Vázquez de Espinosa, A.

1967 Compendio y descripción de las Indias Occidentales, Biblioteca de Autores Españoles, vol. 231, Madrid.

[1629]

Fecha de recepción: 30/05/2016

Fecha de aceptación: 07/02/2017 
